\title{
Characterization of Zebrafish Pax1b and Pax9 in Fin Bud Development
}

\author{
Xuemei Chen, ${ }^{1,2}$ Huizhe Huang, ${ }^{1}$ Hua Wang, ${ }^{3}$ Fengjin Guo, ${ }^{1}$ Xiaogang Du, ${ }^{4}$ \\ Linqiang Ma, ${ }^{1}$ Liang Zhao, ${ }^{1}$ Zhuma Pan, ${ }^{1}$ Haibo Gui, ${ }^{1,2}$ Taixian Yuan, ${ }^{1}$ Xin Liu, ${ }^{3}$ \\ Lin Song, ${ }^{3}$ Yiquan Wang, ${ }^{3}$ Junling He, ${ }^{4}$ Han Lei, ${ }^{1,5}$ and Rui Gao ${ }^{1}$ \\ ${ }^{1}$ Faculty of Basic Medical Sciences, Chongqing Medical University, Medical College Road 1, Chongqing 400016, China \\ ${ }^{2}$ Emergency Department, The First Affiliated Hospital of Chongqing Medical University, Youyi Road 1, Chongqing 400042, China \\ ${ }^{3}$ School of Life Sciences, Xiamen University, South Xiang'an Road, Xiamen 361102, China \\ ${ }^{4}$ Department of Nephrology, The First Affiliated Hospital of Chongqing Medical University, Youyi Road 1, Chongqing 400042, China \\ ${ }^{5}$ Department of Cardiology, The First Affiliated Hospital of Chongqing Medical University, Youyi Road 1, Chongqing 400042, China
}

Correspondence should be addressed to Han Lei; xiaoban@cqmu.edu.cn and Rui Gao; devbiology@cqmu.edu.cn

Received 3 April 2014; Revised 31 May 2014; Accepted 1 July 2014; Published 13 August 2014

Academic Editor: Bryan Crawford

Copyright (c) 2014 Xuemei Chen et al. This is an open access article distributed under the Creative Commons Attribution License, which permits unrestricted use, distribution, and reproduction in any medium, provided the original work is properly cited.

\begin{abstract}
Both Pax1 and Pax9 belong to the important paired box gene family (PAX), which mainly participates in animal development and sclerotome differentiation. To date, the precise molecular mechanism and related signaling pathway of Paxl remain unclear. In our study, microinjection of morpholino- (MO-) modified antisense oligonucleotides against paxlb induced pectoral fin bud defects. Furthermore, we demonstrate that the phenotypes caused by the knockdown of Paxlb in zebrafish could not be phenocopied by pax9 MO and could not be rescued by either Paxla or Pax9 overexpression. We further find that Paxlb affects the expression of col2a1, Uncx4.1, Noggin3, and aggrecan, confirming the role of Paxlb in chondrocyte differentiation and bone maturation. Moreover, we identify an interaction between PAX1 and FOXO1 and find that the interaction was enhanced under hypoxia stress. Together, this evidence for cell death caused by paxlb knockdown provides new insight into the role of the Pax protein family in cell fate determination and tissue specification.
\end{abstract}

\section{Introduction}

The Pax protein family, consisting of numerous transcription factors with a paired box domain containing 128 amino acids, plays a central role in embryonic patterning and organ differentiation [1]. In vertebrates, Pax genes are divided into four subfamilies according to their structures. The Paxl/9 subfamily participates in the formation of skeletal muscle and sclerotome differentiation $[2,3]$.

In most vertebrates, Paxl and Pax9 have similar expression patterns and functions. For example, the expression of both chicken $P A X 1$ and $P A X 9$ genes was the strongest in undifferentiated cells of precartilage condensations or at the margins of differentiated cartilages and was absent from cartilage itself [4]. Both induce chondrogenic differentiation in the sclerotome via targeting Nkx3.2 [5]. Murine PAX1 and $P A X 9$ have overlapping expression profiles and respond to fibroblast growth factor (FGF) and hedgehog (HH) signaling during the progression of limb bud formation [6]. More interestingly, there are four kinds of spontaneous Pax1 mutant mice $\left(\operatorname{Paxl}^{u n}, \operatorname{Pax}^{u n-e x}, \operatorname{Paxl}^{u n-i}\right.$, and $\operatorname{Paxl}^{U n-s}$ ) which show different phenotypes [7]. It has been reported that $P A X 1$ is a candidate gene in vertebral malformations and congenital scoliosis from the study of clinical genetics and the mouse mutant undulated $[8,9]$. Using the teleost medaka, a closely related species to zebrafish, Japanese scientists determined the similarity of pax 1 and pax 9 expression patterns in the sclerotome and pharyngeal pouch. MO knockdown of either Paxl or Pax9 causes defects in the neural arch and scoliosis and double knockdown revealed that Pax1 and Pax9 function synergistically in sclerotome development [10]. 
However, the expression patterns of pax1b and pax9 in zebrafish are quite different. paxib is a maternally expressed gene and is zygotically expressed in the pharyngeal pouches, fin bud, and notochord and weakly expressed in the dorsal aorta and axial vein at $48 \mathrm{hpf}$ [11], while pax 9 is expressed after segmentation, primarily in part of the somites and branchial arches and not in the fin bud (ZFIN). These differences in their expression patterns suggest divergent functions in transcriptional activity and cell differentiation between Paxlb and Pax9 in zebrafish. To address whether the functions of Paxlb and Pax9 have distinct roles in zebrafish embryonic development, we designed two morpholinos (MOs) against paxib and pax9 to study their mechanism of action.

FOXO1, a member of the Forkhead family proteins of the O subclass, is not only one of the most critical regulators of cell death [12], but also an early molecular regulator during mesenchymal cell differentiation into osteoblasts. In mouse embryos, the expression of FoxO1 is higher in skeletal tissues, and FoxO1 silencing has a drastic impact on skeletogenesis and craniofacial development [13]. Gene fusions involving $P A X 3 / 7$ and FOXO1 in alveolar rhabdomyosarcoma have been reported [14]; however, the interaction between PAX1 and the FOXO family has not yet been described. In this research, we studied the relationship between PAX1 and FOXO1 to determine whether FOXO1 participates in the developmental processes regulated by Paxl.

\section{Materials and Methods}

2.1. Fish Maintenance and Embryo Collection. Zebrafish (Danio rerio), $\mathrm{AB}$ strain, were kept at $28.5^{\circ} \mathrm{C}$ under a light and dark cycle of 14 and 10 hours, respectively. Embryos were collected and staged as described [15].

2.2. Plasmid Construction. The paxib cDNA sequence was deposited in GenBank with an accession number of XM_ 695785. The full coding sequence of pax $1 b$ was amplified from cDNAs derived from $24 \mathrm{hpf}$ embryos with a forward primer (zp1F: $5^{\prime}$-atgcaaatggatcagacgtac- $3^{\prime}$ ) and a reverse primer (zp1R: $5^{\prime}$-ttatgagtctgagagtccatg- $3^{\prime}$ ) and subcloned into pXT7 and pBlueScript to generate vectors for synthesizing mRNA and antisense RNA probes in vitro, respectively. Zebrafish pax 9 and amphioxus pax1/9 were subcloned using the same strategy as paxib and the primers were as follows: zp9F $\left(5^{\prime}\right.$-atggagccagcctttgg- $\left.3^{\prime}\right)$, zp9R $\left(5^{\prime}\right.$-tcatagagctgaagccaccag$\left.3^{\prime}\right)$, ap1/9F $\left(5^{\prime}\right.$-atgatgaatatggagcaaacatttg- $\left.3^{\prime}\right)$, and ap1/9R $\left(5^{\prime}\right.$-ttatgaggaggaagcggatg- $\left.3^{\prime}\right)$. Expression plasmids were all subcloned into pCMV5 vector with various tags. Template for PCR was cDNA from different species including human, mouse, and zebrafish.

2.3. Reverse Transcription-PCR. To quantify $n k x 3.2$, col2a1, and aggrecan transcripts in embryos, injected embryos were digested at $24 \mathrm{hpf}$ or $48 \mathrm{hpf}$. First strand cDNAs synthesized from total RNA (Trizol from Takara) were used as templates with the SuperScript Kit (Invitrogen). Specific primers with the sequences listed in Supplemental Table 1 (see Supplementary Material available online at http://dx.doi.org/10.1155/2014/309385) were used to amplify markers $[16,17]$. TE buffer was used as negative control. For qPCR assays, fold change for each group of embryos was determined using the delta-delta Ct method. Data were normalized to the control embryos. Quantified mRNA levels were normalized to $\beta$-actin and are presented relative to control embryos.

2.4. RNA Synthesis, Whole-Mount In Situ Hybridization. Capped mRNAs were synthesized using T7 Cap Scribe (Roche) according to the manufacturer's instructions. For preparation of digoxigenin-labeled antisense probe, plasmid containing paxlb cDNA was linearized with KpnI. In situ hybridizations were performed as previously described [18].

2.5. Morpholinos and Microinjection. Four morpholino oligonucleotides were synthesized by Gene Tools (pax1b-MO1: 5'-CATTTGCATTGTGATATTTCCCTAT-3', positioned from 176 to 200 in the ENSDART00000132835 sequence; pax1b-MO2: $5^{\prime}$-CCCGTGTCTCCCGCTAAAGACTGCC$3^{\prime}$, positioned from 84 to 108 in ENSDART00000132835; zebrafish pax9-MO1: $5^{\prime}$-CAAAGGCTGGCTCCATTGCGTTTAG-3', positioned from 136 to 160 in the U40931.1 sequence; and zebrafish pax9-MO2: $5^{\prime}$-GCTGGTAATTATTGCACCGAAGCCG-3', positioned from 47 to 71 in the U40931.1 sequence). The sequence of control $\mathrm{MO}$ is $5^{\prime}$ CCTCTTACCTCAGTTACAATTTATA-3'. All MOs were dissolved in nuclease-free water to make a $20 \mu \mathrm{g} / \mu \mathrm{L}$ stock. Western blots and RT-PCR assays were used to check MO efficiency. All morphants were injected using a 1:1 mixture of the two MOs. mRNAs and morpholino oligonucleotides were injected into the yolk of fertilized eggs at the single-cell stage [16].

2.6. Cell Culture and Cell Death Assay. Mammalian cells were grown in DMEM (GIBCO) supplemented with $10 \%$ fetal calf serum (Hyclone). In the DNA damage induced cell death assay, U2OS cells were exposed to lethal treatments ( $80 \mathrm{~J} / \mathrm{m}^{2} \mathrm{UV}$ or $2.5 \mu \mathrm{M}$ doxorubicin) and were kept in culture medium for $8 \mathrm{~h}$ before Hoechst staining. The positive cell numbers in 10 random sweeps were summed, and an error bar was calculated from 3 independent replications in each panel [19]. pax1b DNA induction was mediated by the IRESTOMATO lentivirus system.

2.7. Western Blot, Immunoprecipitation, and Immunofluorescence Staining. $36 \mathrm{hpf}$ embryos and 293FT cells were lysed with lysis buffer [18]. The total lysis was mixed with an equal volume of $2 \times$ SDS sample buffer and was analyzed by Western blotting. Antibodies used are the following: rabbit polyclonal antibody to Paxl (83312 from Abcam), Uncx4.1 (ARP47548 from Aviva Systems Biology), Noggin3 (16054 from Abcam), and FOXO1 (sc-11350 from Santa Cruz) and mouse monoclonal antibody to Flag (F1804 from Sigma) or Myc (M4439 from Sigma). For immunoprecipitation, anti-Flag M2 affinity gel was purchased from Sigma. For immunofluorescence staining, 24-36 h after transfection with or without hypoxia stimulation, HeLa cells grown on coverslips were fixed with 
$4 \%$ formaldehyde for $20 \mathrm{~min}$ at room temperature, followed by $0.5 \%$ Triton X-100 treatment for $5 \mathrm{~min}$ and $3 \%$ BSA blocking. The cells were then incubated with corresponding primary and secondary antibodies along with DAPI staining for visualization of nuclei. Fluorescence images were acquired with a Nikon microscope. Fluorescent secondary antibodies, Alexa Fluor 546 (A10040), and FITC-Goat anti-mouse antibody (62-6511) were purchased from Invitrogen.

2.8. Hypoxia Treatment. 293FT and HeLa cells were treated with $\mathrm{CoCl}_{2}$, a well-known hypoxia mimetic agent [20] at different concentrations $(2,20,200$, and $400 \mu \mathrm{mol} / \mathrm{L})$ for $14 \mathrm{~h}$.

2.9. Statistical Analysis. Data are presented as means $\pm \mathrm{SE}$. Differences between treatment groups were analyzed using ANOVA. Differences were considered significant at the $P<$ 0.05 level.

2.10. Ethics Statement. Our experiments were conducted with the permission of the ethics committee of Chongqing Medical University.

\section{Results}

3.1. Paxib Is Required for Zebrafish Morphogenesis and Embryonic Development. In the context of bone mineralization and sclerotome differentiation, few studies to date have examined Paxlb function in zebrafish. We designed two MOs against pax $1 b$ to block its translation (Figure S1). Western blot assays and RT-PCR showed that the bands in the 2nd and 3rd lanes had reduced signals with respect to the control lane (Figure S2A), confirming the efficiency of paxib MOs on protein and RNA levels, respectively. Zebrafish embryos injected with 2 ng paxib MO showed small eyes as well as a curved axis and tail, while $5 \mathrm{ng}$ paxib MO caused more severe phenotypes: head atrophy and a shorter body axis, indicating that the paxlb MO functions in a dose-dependent manner (Figures $1(\mathrm{~b})$ and $1(\mathrm{c}))$.

To test the specificity of paxib MOs, we carried out coinjection of pax $1 b$ mRNA and paxib MO and found that $200 \mathrm{ng}$ of paxib mRNA could rescue paxib morphants to normal axial length, while $g f p$ mRNA could not rescue the axis defects at any concentration (Figures $1(\mathrm{~d})-1(\mathrm{~g})$ ). Interestingly, paxla, the closest homologue of paxib, could not rescue pax $1 b$ morphants in our experiments, neither could amphioxus pax1/9 nor could zebrafish pax9, the other member of the paxl/9 subfamily (Figure $1(\mathrm{~h})$ ). These results indicated that, compared with paxla and zebrafish pax9, pax1b plays different roles in early embryonic development and teleost Pax family members have more diverse and complex functions than previously shown.

3.2. Pax9 Inhibition Causes a Tail Defect. Two MOs against zebrafish pax9 were designed (Figure S1). Due to the lack of a Pax9 antibody, we verified zebrafish pax9 MO efficiency using its target $n k x 3.2$ (Figure S2B). As expected, the knockdown of zebrafish pax9 downregulated $n k x 3.2$ transcription, confirming the efficiency of pax9 MOs. Zebrafish pax9 morphants have different phenotypes than paxib morphants. pax1b morphants showed short body axis and a fin bud defect; however, zebrafish pax9 morphants only showed a kinked tail. Coinjection of paxib andzebrafish pax9 MO showed all of the defects mentioned above (Figures 2(a)-2(d)). The tail defect in zebrafish pax 9 morphants could be rescued only by zebrafish pax 9 mRNA, while the aberrant phenotype could not be rescued by mRNA of members of the same subfamily, paxla and pax $1 b$. These results further confirm that pax1 and pax9 have unique functions in zebrafish embryo development.

3.3. Loss of Function of Zebrafish paxib Causes Fin Bud Defects. Compared with the control group, single-cell stage injection of $2 \mathrm{ng}$ paxib MO caused moderate defects, with smaller and asymmetric pectoral fin in 55\% of embryos, and severe defects including the almost complete lack of fin buds in $27 \%$ of embryos. Embryos injected with $5 \mathrm{ng}$ pax1b MO had more serious phenotypes: fin buds were nearly abolished in about 52\% pax1b morphants (Figures 3(a)-3(c) and $3(\mathrm{e}))$. Coinjection of pax $1 b \mathrm{MO}$ and pax $1 b \mathrm{mRNA}$ rescued the aberrant phenotypes, confirming the specificity of the pax1b MO (Figure 3(d)). In order to further characterize the observed phenotypes, we evaluated the expression of the pectoral fin markers erm and pea3, as means to assess defects in fin bud development. In paxib morphants at $28 \mathrm{hpf}$, the expression of erm and pea3 was dramatically reduced. Coinjection of pax $1 b \mathrm{MO}$ and pax $1 b$ mRNA rescued the defects (Figures $3(\mathrm{f})-3(\mathrm{~m})$ ). These data confirm that pax $1 b$ plays a vital role in zebrafish fin bud development.

3.4. Paxib Controls Bone Maturation. Further investigation at the molecular level found that collagen type II (col2al), a chondrocyte differentiation marker, was downregulated in pax1b morphants (Figure 4(a)), suggesting that chondrocytes differentiation was affected in pax $1 b$ morphants. Using polyclonal antibodies against Noggin3 and Uncx4.1, we found that the protein level of Uncx4.1 was downregulated, while Noggin3 was upregulated in pax1b morphants (Figure 4(b)). Due to a lack of available antibody against Aggrecan, we detected its transcript and found a significant reduction in pax1b morphants (Figure 4(c)). These results suggested that pax $1 b$ correlates with the progression of bone maturation.

3.5. Forced Expression of Paxlb Decreases Cell Death Potential on Physiological Stress. The obvious fin bud defects in paxib morphants led us to investigate whether Paxlb affected cell death in an overexpression system. A range of biological stressors or DNA damage can induce cell death. In control cell culture, UV treatment with $80 \mathrm{~J} \mathrm{~m}^{-2}$ dose induced $72.0 \%$ cell death in the U2OS cell line, but transfection of $0.5 \mu \mathrm{g}$ or $1.5 \mu \mathrm{g}$ Pax $1 b$ DNA reduced this rate to $49.2 \%$ and $42.9 \%$, respectively (Figure 5(a)). Consistently, $2.5 \mu \mathrm{M}$ doxorubicin caused $76.4 \%$ U2OS cell death; transfection of $0.5 \mu \mathrm{g}$ or $1.5 \mu \mathrm{g}$ Paxlb DNA decreased this ratio to $55.9 \%$ and $48 \%$, respectively (Figure 5(b)). Thus, Paxlb serves as a cell death inhibitory molecule, and its knockdown might increase apoptosis or other types of cell death. 


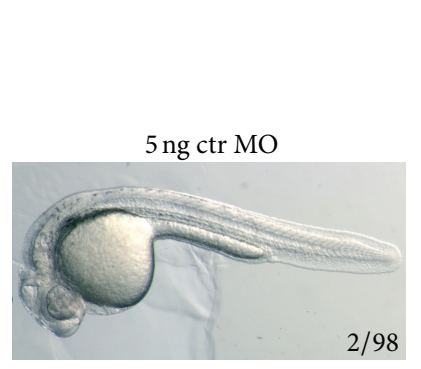

(a)

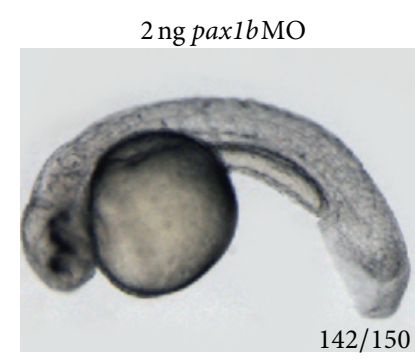

(b)

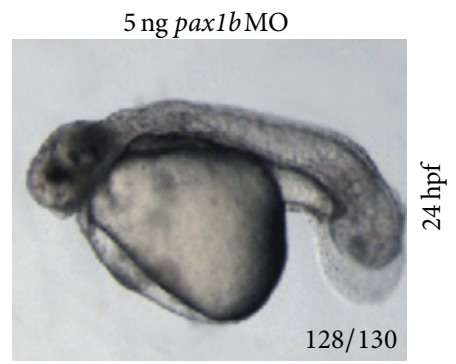

(c)



(d)

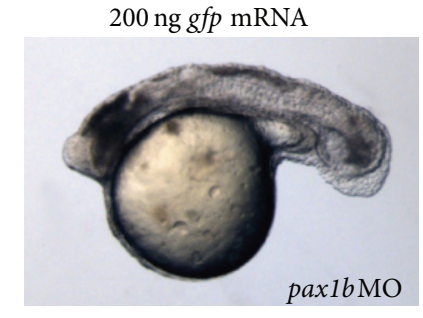

(e)

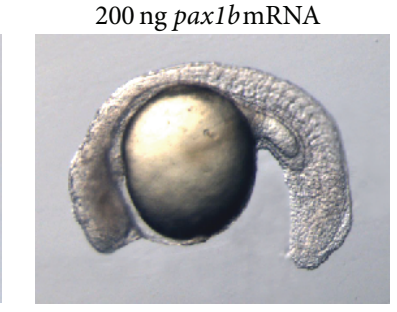

(f)

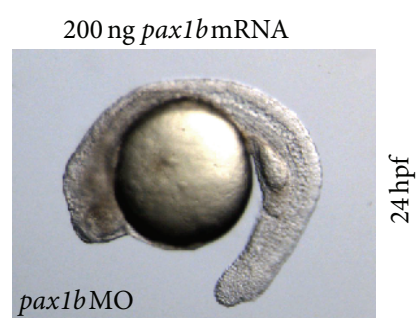

(g)

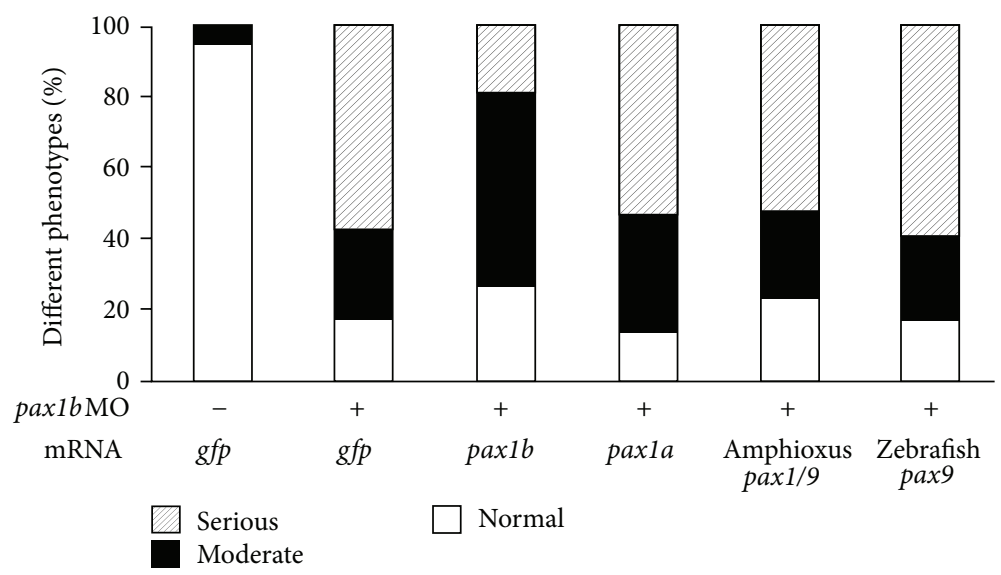

(h)

Figure 1: Phenotype caused by pax $1 b$ knockdown. In order to analyze the function of pax $1 b$ during embryogenesis, we injected pax $1 b$-specific morpholinos into fertilized eggs to block production of functional Paxlb protein. (a) Embryo injected with 5 ng control morpholino. ((b)(c)) The phenotypes of paxlb morphants caused by $2 \mathrm{ng}$ or $5 \mathrm{ng}$ injection doses. ((d)-(g)) The phenotypes caused by coinjection of $200 \mathrm{ng}$ paxlb or $g f p$ mRNA with $5 \mathrm{ng}$ paxlb MO or control MO. paxlb mRNA could partially rescue the defective fin bud phenotype of the paxib morphant (g); $g f p$ mRNA failed to rescue defective fin bud phenotype of the paxib morphant (e). (h) Statistical analysis of phenotypes caused by coinjection of different mRNAs with $5 \mathrm{ng}$ paxlb MO. 150 embryos were calculated. The amount of mRNA injected for every embryo is as follows: $200 \mathrm{ng} g f p$ mRNA, $200 \mathrm{ng}$ paxlb mRNA, $200 \mathrm{ng}$ paxla mRNA, $150 \mathrm{ng}$ amphioxus paxl/9 mRNA, and $200 \mathrm{ng}$ zebrafish pax 9 mRNA. All embryos were observed at 24 hpf. zpaxlb: zebrafish paxlb, zpaxla: zebrafish paxla, zpax9: zebrafish pax9. hpf: hours post-fertilization. gfp: green fluorescence protein. ctr: control.

3.6. PAX1 Interacts with FOXO1. We studied the relationship between PAX1 and FOXO1 using immunoprecipitation assays. Results showed that PAX1 interacts with FOXO1 in HEK293FT cells and that the interaction is conserved in different species including human, mouse, and zebrafish (Figures 6(a) and 6(b)). However, there was no interaction between PAX9 and FOXO1 (Figure 6(c)).

We next tested the subcellular localization of PAX1 and FOXO1. Immunofluorescence assays revealed that PAX1 was only located at the nucleus while FOXO1 was distributed in both the cytoplasm and nucleus. Moreover, the colocalization of PAX1 and FOXO1 increased when stimulated with $\mathrm{CoCl}_{2}$ (Figure 7(a)). Further coimmunoprecipitation analysis showed that hypoxia stress enhanced the interaction between PAX1 and FOXO1 in a dose-dependent manner (Figures 7(b) and $7(\mathrm{c})$ ). Taken together, these data provide evidence that Paxl might participate in fin bud development together with FOXO1. 


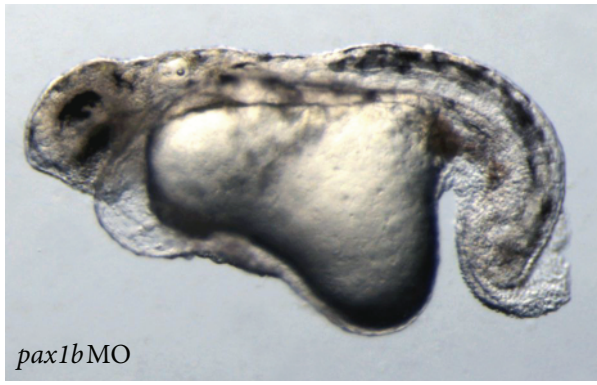

(a)

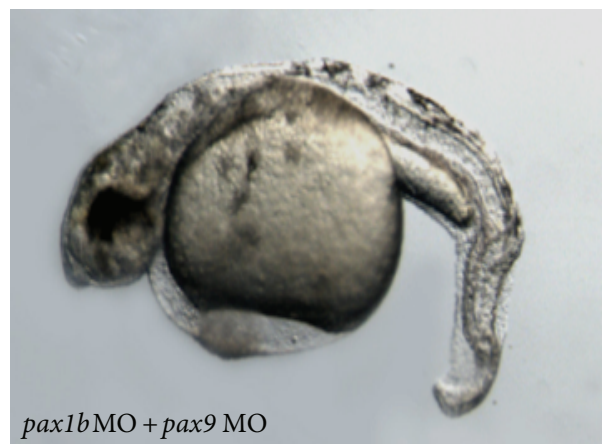

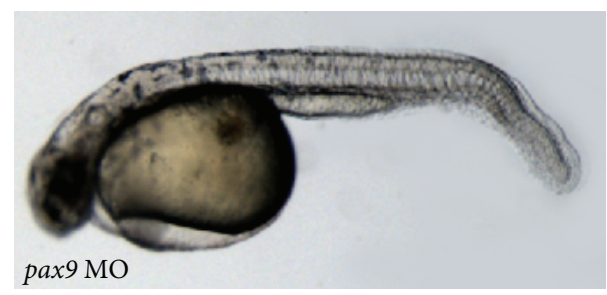

(b)



FB defect

Kinky tail

(c)

(d)

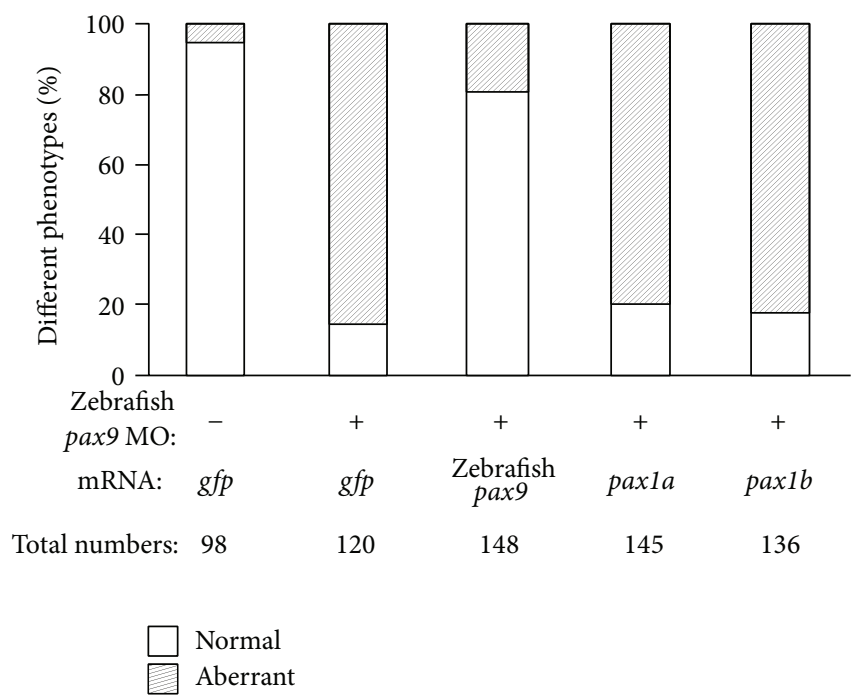

(e)

FIGURE 2: Fin bud and tail defects caused by injection of pax1b MO and/or zebrafish pax 9 MO. (a) Fin bud and axis defects caused by injection of $5 \mathrm{ng}$ paxlb MO. (b) Tail defect caused by injection of $5 \mathrm{ng}$ zebrafish pax 9 MO. (c) Fin bud and tail defects caused by coinjection of $2.5 \mathrm{ng}$ paxlb MO and $2.5 \mathrm{ng}$ zebrafish pax $9 \mathrm{MO}$. (d) Statistics of phenotype ratios. White columns indicate the ratio of fin bud defect; shaded columns indicate the ratio of kinky tail. (e) Statistical analysis of phenotypes caused by coinjection of different mRNAs with $5 \mathrm{ng}$ zebrafish pax 9 MO. The amount of mRNA injected for every embryo is as follows: $200 \mathrm{ng} g f p$ mRNA, $200 \mathrm{ng}$ paxlb mRNA, $200 \mathrm{ng}$ paxla mRNA, and $200 \mathrm{ng}$ zebrafish pax 9 mRNA. All embryos were observed at $36 \mathrm{hpf}$. 


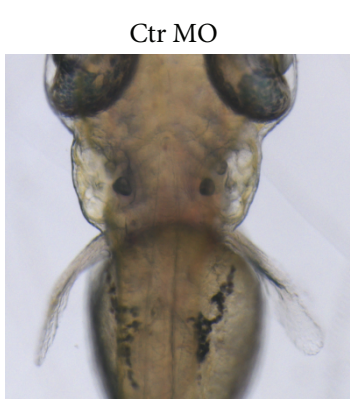

(a)

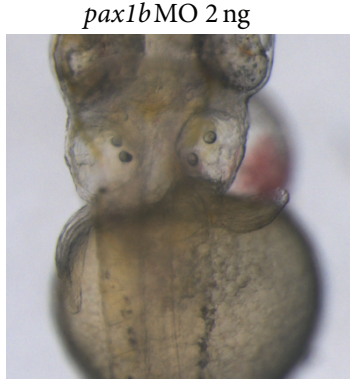

(b)



(c)

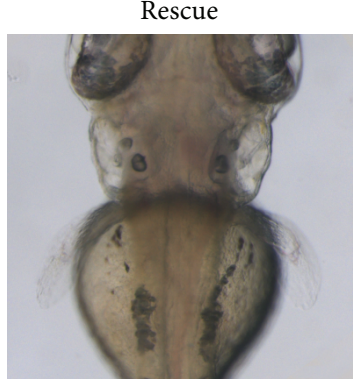

(d)

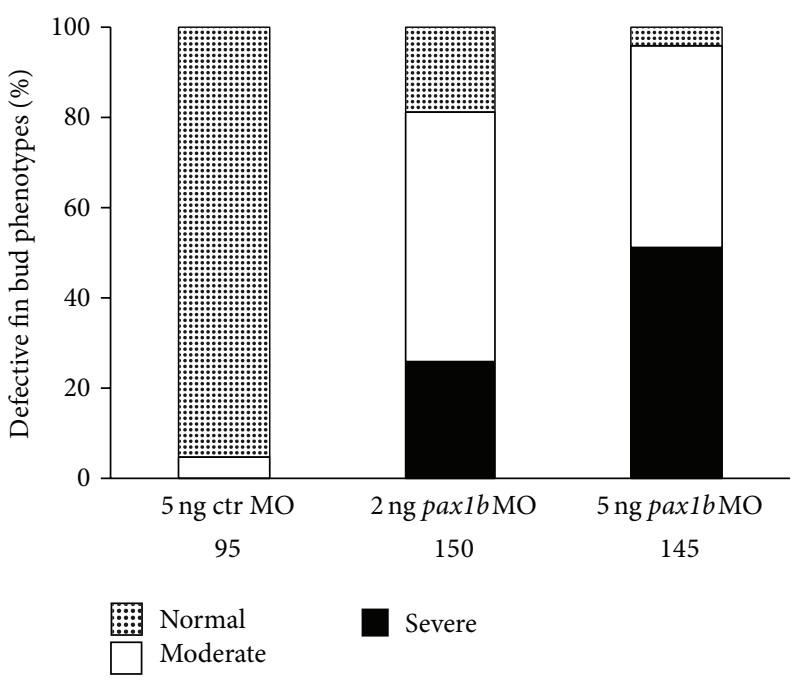

(e)

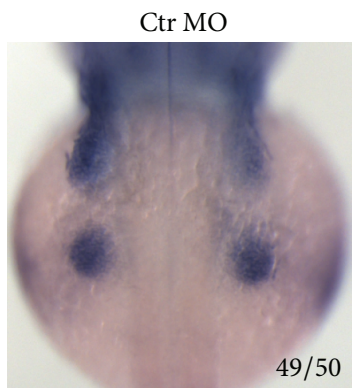

(f)

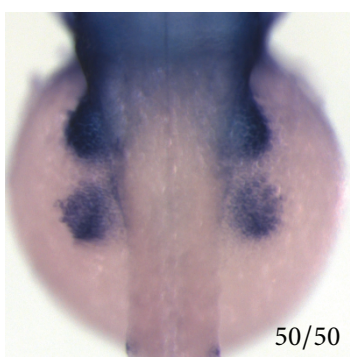

(j)

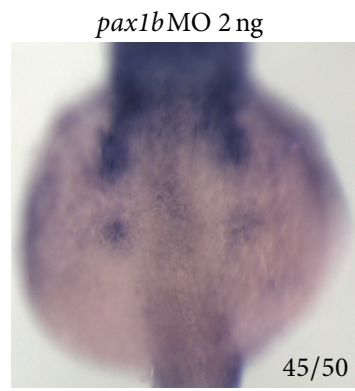

(g)

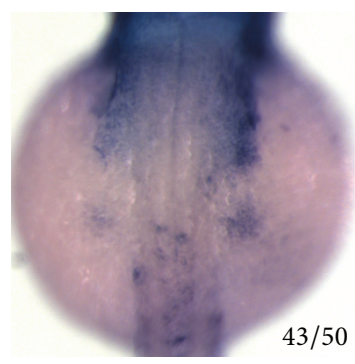

(k)

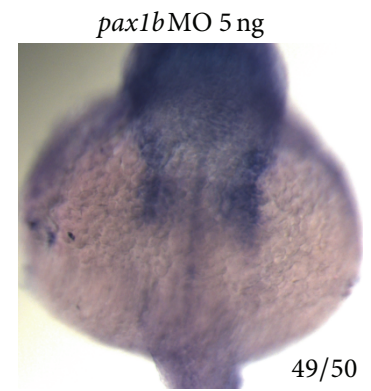

(h)

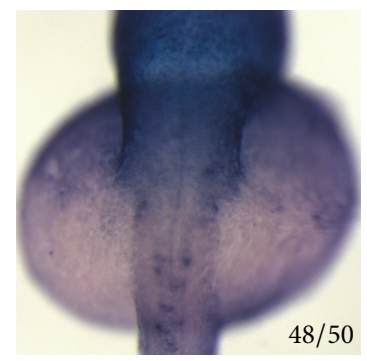

(1)

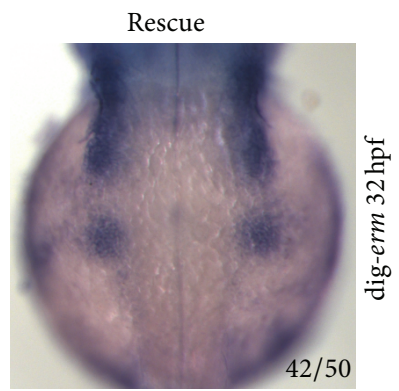

(i)

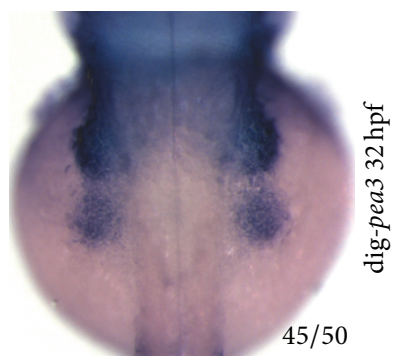

(m)

FIgURE 3: Fin bud defects caused by paxlb knockdown. ((a)-(d)) Dorsal view of the region near the fin bud with orientation of head towards the top. (a) Control embryos. ((b)-(c)) pax1b morphants. (d) Rescue embryos: coinjection with $5 \mathrm{ng}$ pax1b MO and $200 \mathrm{ng}$ pax1b mRNA. (e) Statistical analysis of fin bud defects caused by injection of control MO or paxlb MO. Total numbers of injected embryos are labeled. ((f)-(m)) Expression pattern of erm and pea3 in control embryos, pax $1 b$ morphants, and coinjected embryos. Numbers of defective embryos and total numbers of stained embryos are labeled in the bottoms. The embryonic stage is $72 \mathrm{hpf}$ in panels (a)-(e) and $32 \mathrm{hpf}$ in panels (f)-(m). All the embryos are viewed from the dorsal side with head towards the top. 


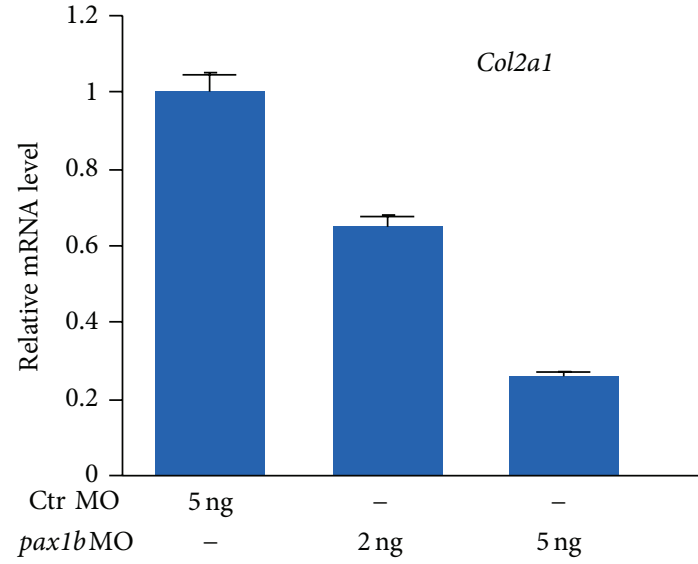

(a)

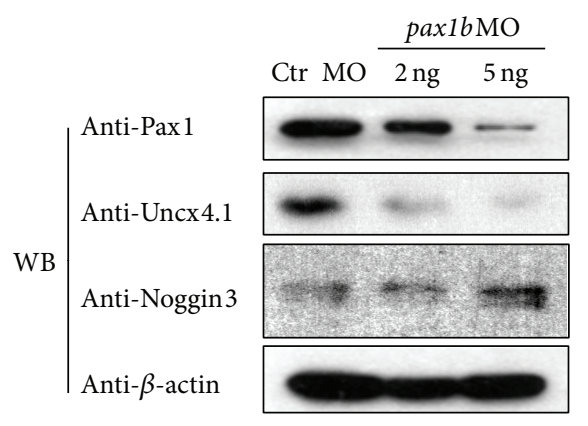

(b)

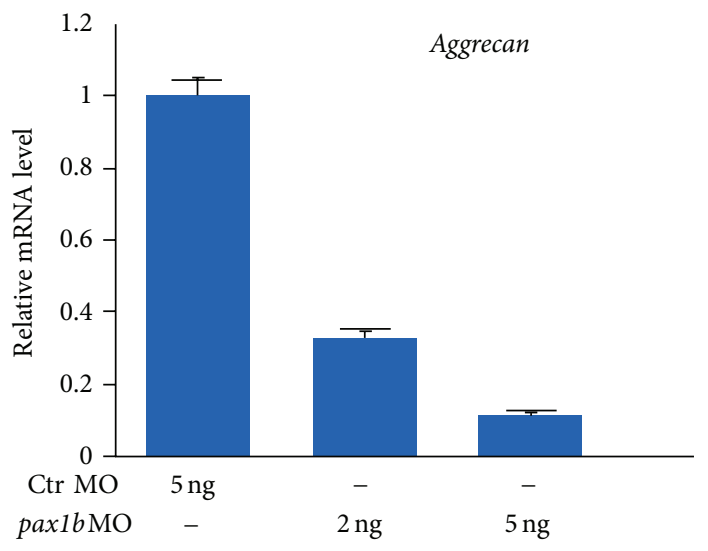

(c)

Figure 4: Molecular mechanism of sclerotome development mediated by Paxlb. (a) The relative expression level of zebrafish collagen type II (col2al) monitored by qPCR. (b) Sclerotome differentiation analyzed by molecular markers Uncx4.1 and Noggin3 by Western blot. (c) The relative expression level of zebrafish aggrecan monitored by qPCR. The fold change for each group was determined using the delta-delta $\mathrm{Ct}$ method. Quantified mRNA levels were normalized to $\beta$-actin and are presented relative to control embryos. 50 embryos at the 48 hpf stage were used in each group, performed in triplicate.

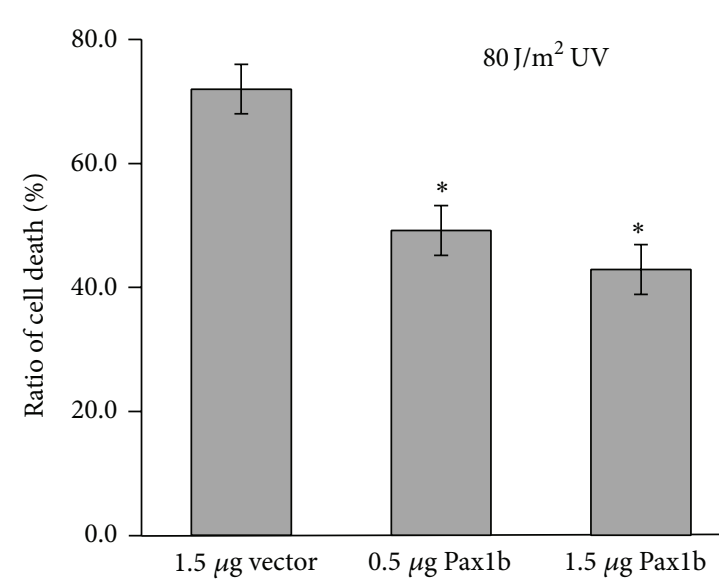

(a)

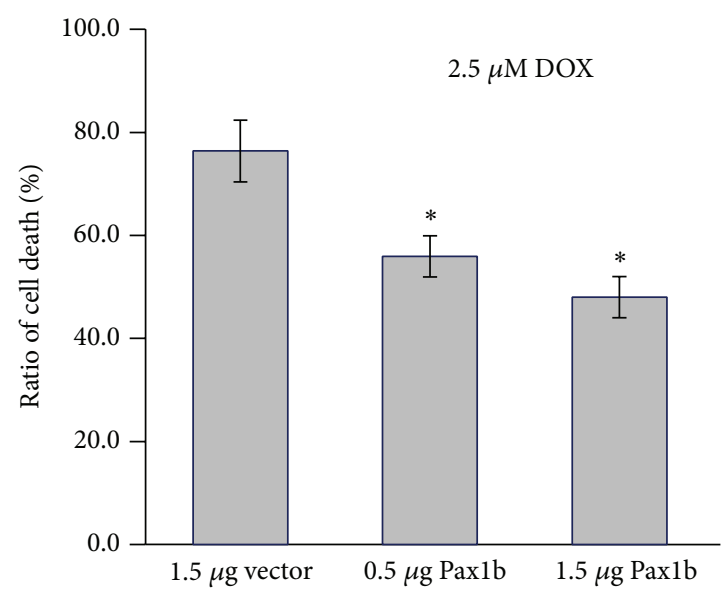

(b)

FIGURE 5: Forced expression of Paxl decreases cell death potential on physiological stress. U2OS cells were exposed to $80 \mathrm{~J} / \mathrm{m}^{2} \mathrm{UV}$ (a) or $2.5 \mu \mathrm{M}$ doxorubicin (b) for $8 \mathrm{~h}$. Hoechst-positive cells were counted and subjected to statistical analysis using Student's $t$-tests. All paxib DNA induction was mediated by the IRES-TOMATO lentivirus system. Data are presented as means \pm SE from three independent experiments. ${ }^{*} P<0.05$, compared with vector. 


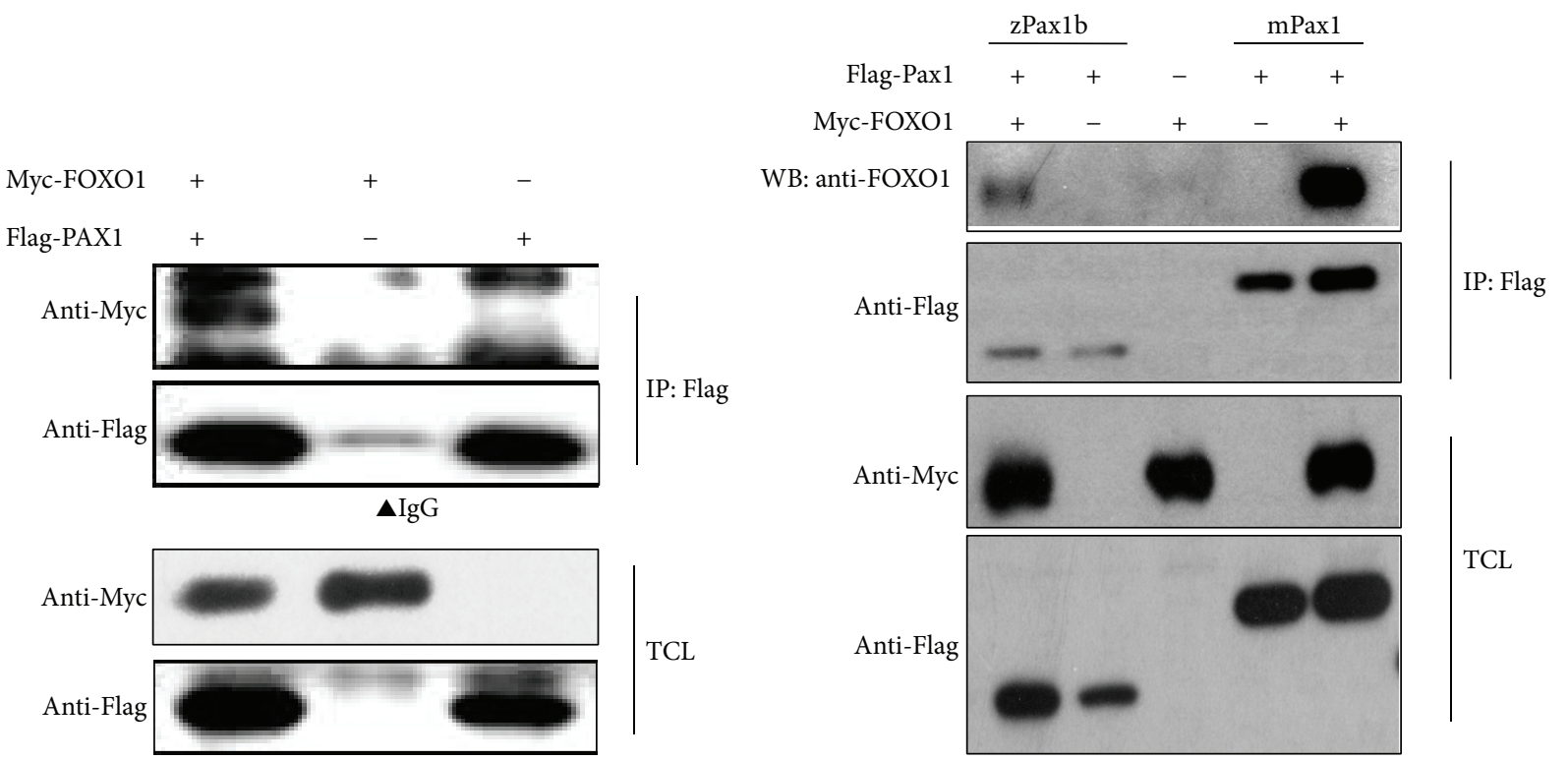

(a)

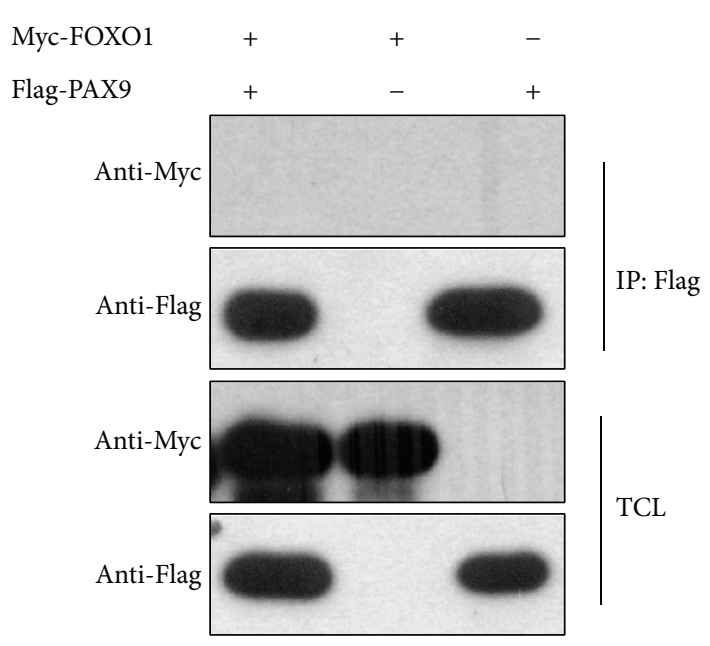

(b)

(c)

FIgURE 6: The interaction between PAX1 and FOXO1. (a) FOXO1 is a new PAX1-interacting protein. HEK293FT cells were transfected with Myc-tagged FOXO1 and Flag-tagged PAX1 cloned from human cDNA. Cells were harvested for immunoprecipitation with anti-Flag affinity resin and immunoblotted with the indicated antibodies. (b) The interaction of Paxl and FOXO1 was conserved. Myc-tagged FOXO1 was immunoprecipitated by Flag-tagged Paxlb or mouse Paxl. (c) PAX9 did not interact with FOXO1 in HEK293FT cells. zPaxlb: zebrafish Paxlb; mPaxl: mouse Paxl. TCL: total cell lysate. IP: immunoprecipitation.

\section{Discussion}

The PAX protein family was first identified almost thirty years ago [21]. We used MEGA4.0.2 software to do a phylogenetic analysis and found that there are high identities among Homo sapiens Paxl, Mus musculus Paxl, Xenopus Paxl, Danio rerio Paxl, Danio rerio Pax9, and Branchiostoma Paxl/9 (Figure S3). The amino acid alignment performed by DNAssist software indicated that the amino acid sequence is highly conserved among Branchiostoma Pax1/9, Danio rerio Paxla, and Danio rerio Paxlb as well as Danio rerio Pax9 (Figure S4). The knockout of Pax1 in mouse produced malformed sternum and scapula [7]. In this report, we used zebrafish as an animal model to investigate the biological functions of Paxlb and Pax9, demonstrating that paxib morphants display serious defects in fin buds and the axis which is different than pax 9 morphants. Paxlb overexpression rescued the morphants to a moderate phenotype, whereas Paxla or zebrafish Pax9 could not rescue paxib morphants. On the other hand, several reports have revealed differences between undulated mutations of Paxl and its knockout model, proving the haploinsufficiency of Paxl and redundancy of Pax9 [7, 22]. Moreover, it has been reported that the loss of Pax 9 function in the vertebral column in $\operatorname{Pax} 9^{\text {lacZ }}$ mutant mice might be rescued by Paxl and another report showed that Pax9 might partially substitute for $\operatorname{Paxl}[7,23]$. Our results suggest 
FOXO1-Myc FITC

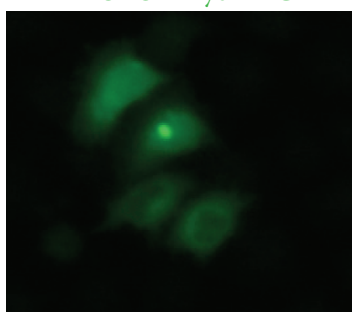

FOXO1-Myc FITC
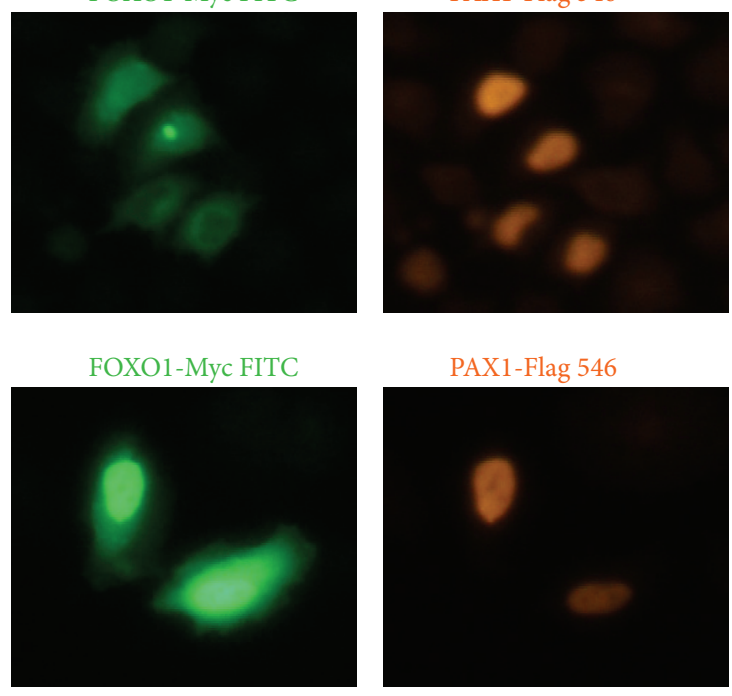

DAPI

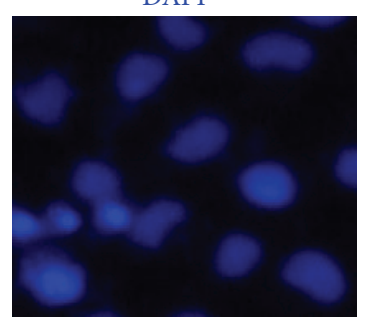

DAPI
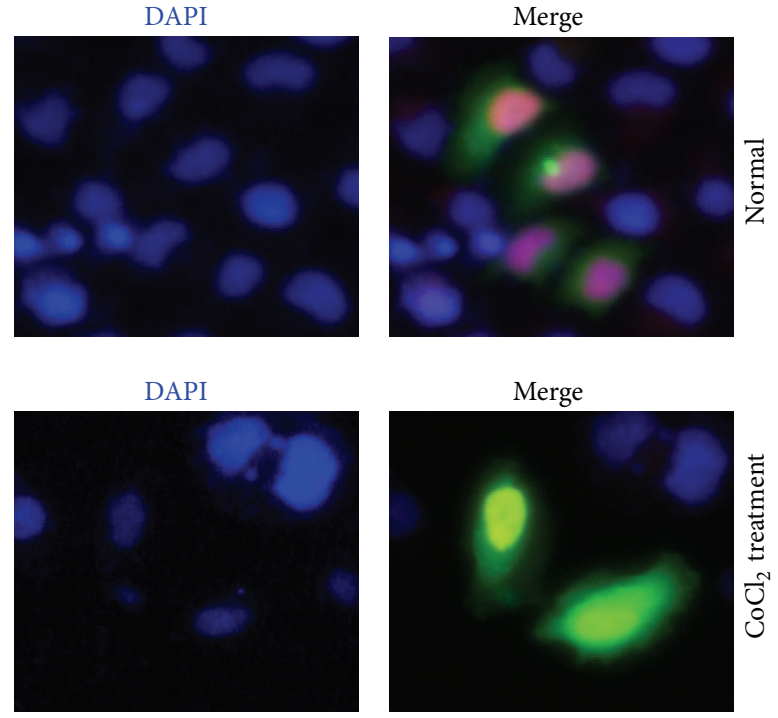

בี

(a)

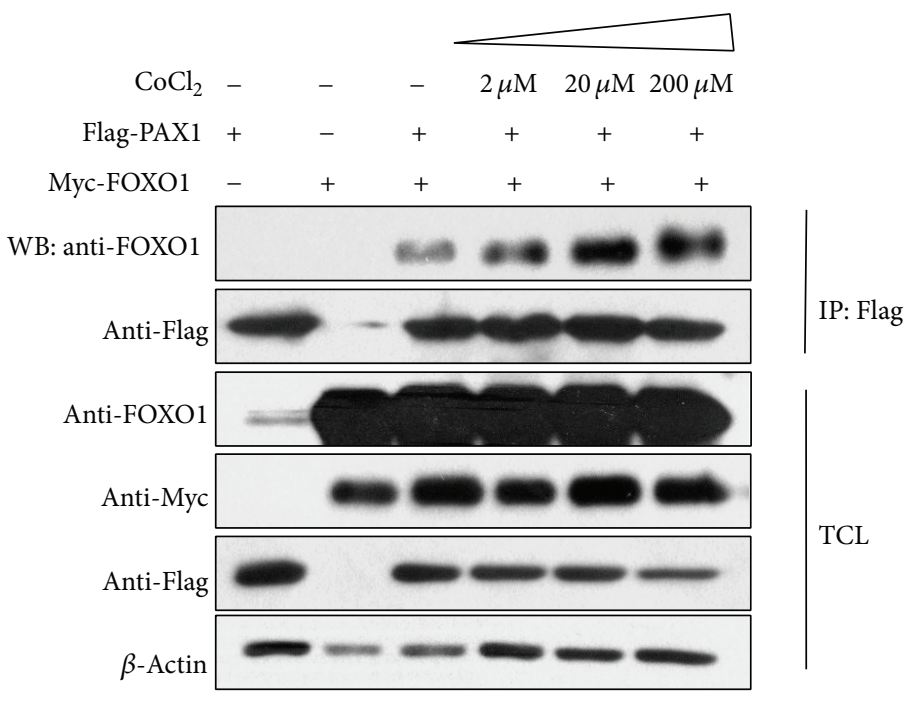

(c)

FIgURE 7: The interaction between PAX1 and FOXO1 is enhanced under hypoxia stress. (a) Colocalization of PAX1 and FOXO1 in HeLa cells. Myc-FOXO1 is distributed in the cytoplasm and nucleus while Flag-PAX1 is located in the nucleus only. The colocalization of PAX1 and FOXO1 was increased after treatment with $20 \mu \mathrm{M} \mathrm{CoCl}_{2}$ for $14 \mathrm{~h}$. Myc-FOXO1 was cotransfected with Flag-PAX1 into HeLa cells. $36 \mathrm{~h}$ after transfection, cells were subjected to immunostaining using anti-Myc antibody, anti-Flag antibody, and DAPI and observed by microscopy. ((b)-(c)) $2 \mu \mathrm{g}$ Flag-tagged PAX1 and/or $0.5 \mu \mathrm{g}$ Myc-tagged FOXO1 were transfected into HEK293FT cells, respectively. Semiendogenous CoIP revealed that the interaction of PAX1 and FOXO1 was strengthened when stimulated with $\mathrm{CoCl}_{2}$ and the enhancement occurred in a dose-dependent manner.

that Paxlb cannot rescue zebrafish pax 9 morphants nor can zebrafish Pax9 rescue paxib morphants which suggests that the divergence of two subfamily members has biological significance and is responsible for the different physiological or environmental stresses in the evolutionary process.

The development of fin buds is related to the formation of cartilage and chondral ossification. The chondrogenic anlage is the main component of the fin bud mesenchyme in zebrafish [24]. Recent research reported that pax $1 b$ knockdown leads to hypoplasia in pharyngeal cartilage [11]. We found that loss of function of paxib in zebrafish downregulated the expression of col2al, a chondrocyte differentiation marker. In the perichondral or endochondral ossification through the cartilage anlagen, Uncx4.1 and Aggrecan served as positive regulators, and Noggin 3 is regarded as negative regulator in this process [25-27]. Our results indicated that the expression of Uncx4.1, Noggin3, and Aggrecan is disturbed in paxib morphants. All of these results confirm that Paxlb plays vital roles in fin bud development.

The size of an organ is largely determined by the number of cells it contains and cell death is an essential aspect in this process [28]. The phenotype of fin bud defects in pax1b 
morphants might have a close relationship with cell death. Previous studies have illustrated that Pax3 and Pax7 are associated with cell survival in numerous cancer cell lines and silencing of pax 2 promotes renal carcinoma apoptosis $[29,30]$. Our original study shows that knockdown of pax $1 b$ induced cell death in the specific tissue of zebrafish embryos and Paxlb overexpression decreased stress-induced apoptosis in the U2OS cell line. FOXOs not only promote mammalian cell survival by inducing cell cycle arrest and quiescence in response to oxidative stress, but also regulate longevity in model organisms [31]. FOXO1 can be phosphorylated by JNK or Mstl proteins, which phosphorylate FOXO1 under conditions of oxidative stress. This phosphorylation causes the translocation of FOXO1 from the cytoplasm to the nucleus [12]. It has been reported that the transcription of FoxO3, another member in the FoxO subfamily, is induced by hypoxia and the increased expression of FoxO3 results in enhanced cellular survival by attenuating HIF-induced apoptosis [32]. We supposed that FOXO1 might play a role in resistance to hypoxic stress during development together with PAX1. In this study, we demonstrate for the first time that PAX1 interacts with FOXO1 and that this interaction is strengthened under hypoxia stress. We postulate that fin bud malformation in paxib morphants is caused by cell death via FOXO1 signaling. The downstream events remain unclear, and much more work is needed in the future to address the exact mechanism.

\section{Conclusions}

In summary, we have discovered that paxib plays a pivotal role in zebrafish fin bud development. Overexpression of pax $1 b$ can relieve cell death induced by stress. Furthermore, we found an interaction between PAX1 and FOXO1 for the first time, an interaction enhanced under hypoxia stress. Together, the evidence for cell death caused by pax $1 b$ knockdown provides new insights into the role of the Pax protein family in cell fate determination and tissue specification.

\section{Conflict of Interests}

The authors declare that there is no conflict of interests regarding the publication of this paper.

\section{Acknowledgments}

This work was supported by Grant from Basic Science Programs of China (no. 2011CB944002) and Grant from National Natural Science Foundation of China (no. 31171388) and Chongqing Excellent Young Scientist Foundation (no. 2012jjjq10001) to Huizhe Huang, National Natural Science Foundation of China (no. 81202318) to Xuemei Chen, National Natural Science Foundation of China (no. 81370816) to Xiaogang Du, and the National High Technology Research and Development Program of China (no. 2008AA092602) to Yiquan Wang.

\section{References}

[1] V. R. Paixão-Côrtes, F. M. Salzano, and M. C. Bortolini, "Evolutionary history of chordate PAX genes: dynamics of change in a complex gene family," PLoS ONE, vol. 8, Article ID e73560, 2013.

[2] L. Z. Holland and N. D. Holland, "Expression of AmphiHox-1 and AmphiPax-1 in amphioxus embryos treated with retinoic acid: insights into evolution and patterning of the chordate nerve cord and pharynx," Development, vol. 122, no. 6, pp. 1829$1838,1996$.

[3] D. Lang, S. K. Powell, R. S. Plummer, K. P. Young, and B. A. Ruggeri, "PAX genes: roles in development, pathophysiology, and cancer," Biochemical Pharmacology, vol. 73, no. 1, pp. 1-14, 2007.

[4] E. E. LeClair, L. Bonfiglio, and R. S. Tuan, "Expression of the paired-box genes Pax-1 and Pax-9 in limb skeleton development," Developmental Dynamics, vol. 214, no. 2, pp. 101-115, 1999.

[5] I. Rodrigo, R. E. Hill, R. Balling, A. Münsterberg, and K. Imai, "Paxl and Pax9 activate Bapxl to induce chondrogenic differentation in the sclerotome," Development, vol. 130, no. 3 , pp. 473-482, 2003.

[6] M. P. O'Rourke, K. Soo, R. R. Behringer, C. Hui, and P. P. L. Tam, "Twist plays an essential role in FGF and SHH signal transduction during mouse limb development," Developmental Biology, vol. 248, no. 1, pp. 143-156, 2002.

[7] B. Wilm, E. Dahl, H. Peters, R. Balling, and K. Imai, “Targeted disruption of Paxl defines its null phenotype and proves haploinsufficiency," Proceedings of the National Academy of Sciences of the United States of America, vol. 95, no. 15, pp. 8692-8697, 1998.

[8] P. F. Giampietro, C. L. Raggio, C. E. Reynolds et al., "An analysis of PAX1 in the development of vertebral malformations," Clinical Genetics, vol. 68, no. 5, pp. 448-453, 2005.

[9] I. M. Adham, M. Gille, A. J. Gamel et al., "The scoliosis (sco) mouse: a new allele of Paxl," Cytogenetic and Genome Research, vol. 111, no. 1, pp. 16-26, 2005.

[10] T. Mise, M. Iijima, K. Inohaya, A. Kudo, and H. Wada, "Function of Paxl and Pax9 in the sclerotome of medaka fish," Genesis, vol. 46, no. 4, pp. 185-192, 2008.

[11] H. W. Xin Liu, G. Li, H.-Z. Huang, and Y.-Q. Wang, “The function of DrPaxlbgene in the embryonic development of zebrafish," Genes and Genetic Systems, vol. 88, pp. 261-269, 2013.

[12] M. E. Carter and A. Brunet, "FOXO transcription factors," Current Biology, vol. 17, no. 4, pp. R113-R114, 2007.

[13] C. C. Teixeira, Y. Liu, L. M. Thant, J. Pang, G. Palmer, and M. Alikhani, "Foxol, a novel regulator of osteoblast differentiation and skeletogenesis," The Journal of Biological Chemistry, vol. 285, no. 40, pp. 31055-31065, 2010.

[14] F. G. Barr, "Gene fusions involving PAX and FOX family members in alveolar rhabdomyosarcoma," Oncogene, vol. 20, no. 40, pp. 5736-5746, 2001.

[15] C. B. Kimmel, W. W. Ballard, S. R. Kimmel, B. Ullmann, and T. F. Schilling, "Stages of embryonic development of the zebrafish," Developmental Dynamics, vol. 203, no. 3, pp. 253-310, 1995.

[16] Y. Cao, J. Zhao, Z. Sun, Z. Zhao, J. Postlethwait, and A. Meng, "fgf17b, a novel member of Fgf family, helps patterning zebrafish embryos," Developmental Biology, vol. 271, no. 1, pp. 130-143, 2004. 
[17] M. E. Robu, J. D. Larson, A. Nasevicius et al., "p53 activation by knockdown technologies," PLoS Genetics, vol. 3, article e78, no. 5, 2007.

[18] B. Xiong, Y. Rui, M. Zhang et al., "Tob1 controls dorsal development of zebrafish embryos by antagonizing maternal beta-catenin transcriptional activity," Developmental Cell, vol. 11, no. 2, pp. 225-238, 2006.

[19] R. Dechend, F. Hirano, K. Lehmann et al., "The Bcl-3 oncoprotein acts as a bridging factor between NF- $\kappa \mathrm{B} /$ Rel and nuclear co-regulators," Oncogene, vol. 18, no. 22, pp. 3316-3323, 1999.

[20] A. Lan, X. Liao, L. Mo et al., "Hydrogen sulfide protects against chemical hypoxia-induced injury by inhibiting ROS-activated ERK1/2 and p38mapk signaling pathways in PC12 cells," PLoS ONE, vol. 6, no. 10, Article ID e25921, 2011.

[21] D. Bopp, M. Burri, S. Baumgartner, G. Frigerio, and M. Noll, "Conservation of a large protein domain in the segmentation gene paired and in functionally related genes of Drosophila," Cell, vol. 47, no. 6, pp. 1033-1040, 1986.

[22] E. J. D. Robson, S. He, and M. R. Eccles, "A PANorama of PAX genes in cancer and development," Nature Reviews Cancer, vol. 6, no. 1, pp. 52-62, 2006.

[23] H. Peters, A. Neubüser, K. Kratochwil, and R. Balling, "Pax9deficient mice lack pharyngeal pouch derivatives and teeth and exhibit craniofacial and limb abnormalities," Genes and Development, vol. 12, no. 17, pp. 2735-2747, 1998.

[24] H. Grandel and S. Schulte-Merker, "The development of the paired fins in the zebrafish (Danio rerio)," Mechanisms of Development, vol. 79, no. 1-2, pp. 99-120, 1998.

[25] B. S. Mankoo, S. Skuntz, I. Harrigan et al., "The concerted action of Meox homeobox genes in required upstream of genetic pathways essential for the formation, patterning and differentiation of somites," Development, vol. 130, no. 19, pp. 4655-4664, 2003.

[26] J. S. Kang, T. Oohashi, Y. Kawakami, Y. Bekku, J. C. Izpisúa Belmonte, and Y. Ninomiya, "Characterization of dermacan, a novel zebrafish lectican gene, expressed in dermal bones," Mechanisms of Development, vol. 121, no. 3, pp. 301-312, 2004.

[27] S. Skuntz, B. Mankoo, M. T. Nguyen et al., "Lack of the mesodermal homeodomain protein MEOX1 disrupts sclerotome polarity and leads to a remodeling of the cranio-cervical joints of the axial skeleton," Developmental Biology, vol. 332, no. 2, pp. 383-395, 2009.

[28] A. E. Catalano, P. A. Raymond, D. Goldman, and X. Wei, "Zebrafish dou yan mutation causes patterning defects and extensive cell death in the retina," Developmental Dynamics, vol. 236, no. 5, pp. 1295-1306, 2007.

[29] A. Muratovska, C. Zhou, S. He, P. Goodyer, and M. R. Eccles, "Paired-Box genes are frequently expressed in cancer and often required for cancer cell survival," Oncogene, vol. 22, no. 39, pp. 7989-7997, 2003.

[30] V. Dormoy, S. Danilin, V. Lindner et al., "The sonic hedgehog signaling pathway is reactivated in human renal cell carcinoma and plays orchestral role in tumor growth," Molecular Cancer, vol. 8, article 123, 2009.

[31] S. C. Manolagas and M. Almeida, "Gone with the Wnts: $\beta$ catenin, T-cell factor, forkhead box $\mathrm{O}$, and oxidative stress in age-dependent diseases of bone, lipid, and glucose metabolism," Molecular Endocrinology, vol. 21, no. 11, pp. 2605-2614, 2007.

[32] D. A. Salih and A. Brunet, "FoxO transcription factors in the maintenance of cellular homeostasis during aging," Current Opinion in Cell Biology, vol. 20, no. 2, pp. 126-136, 2008. 

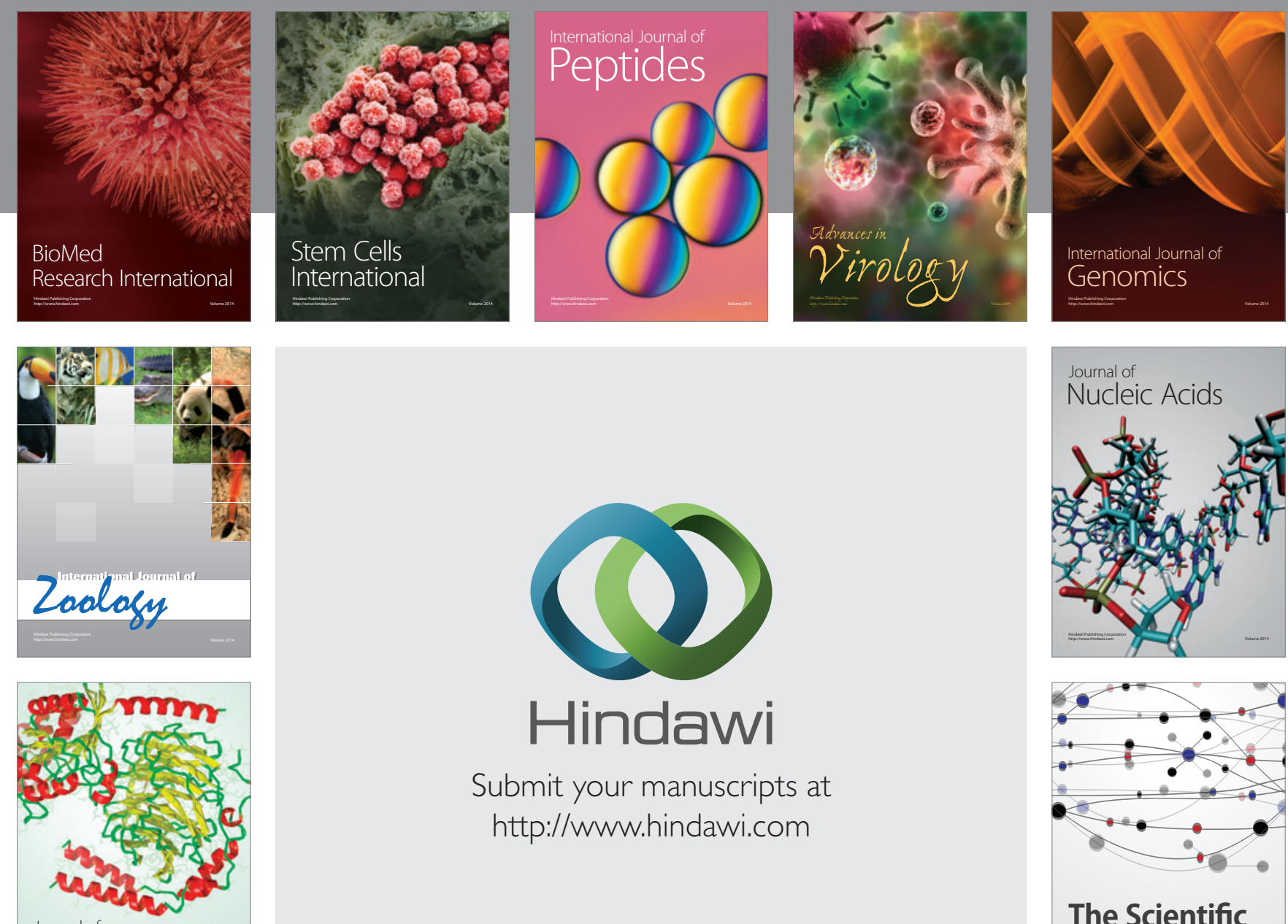

Submit your manuscripts at

http://www.hindawi.com

Journal of
Signal Transduction
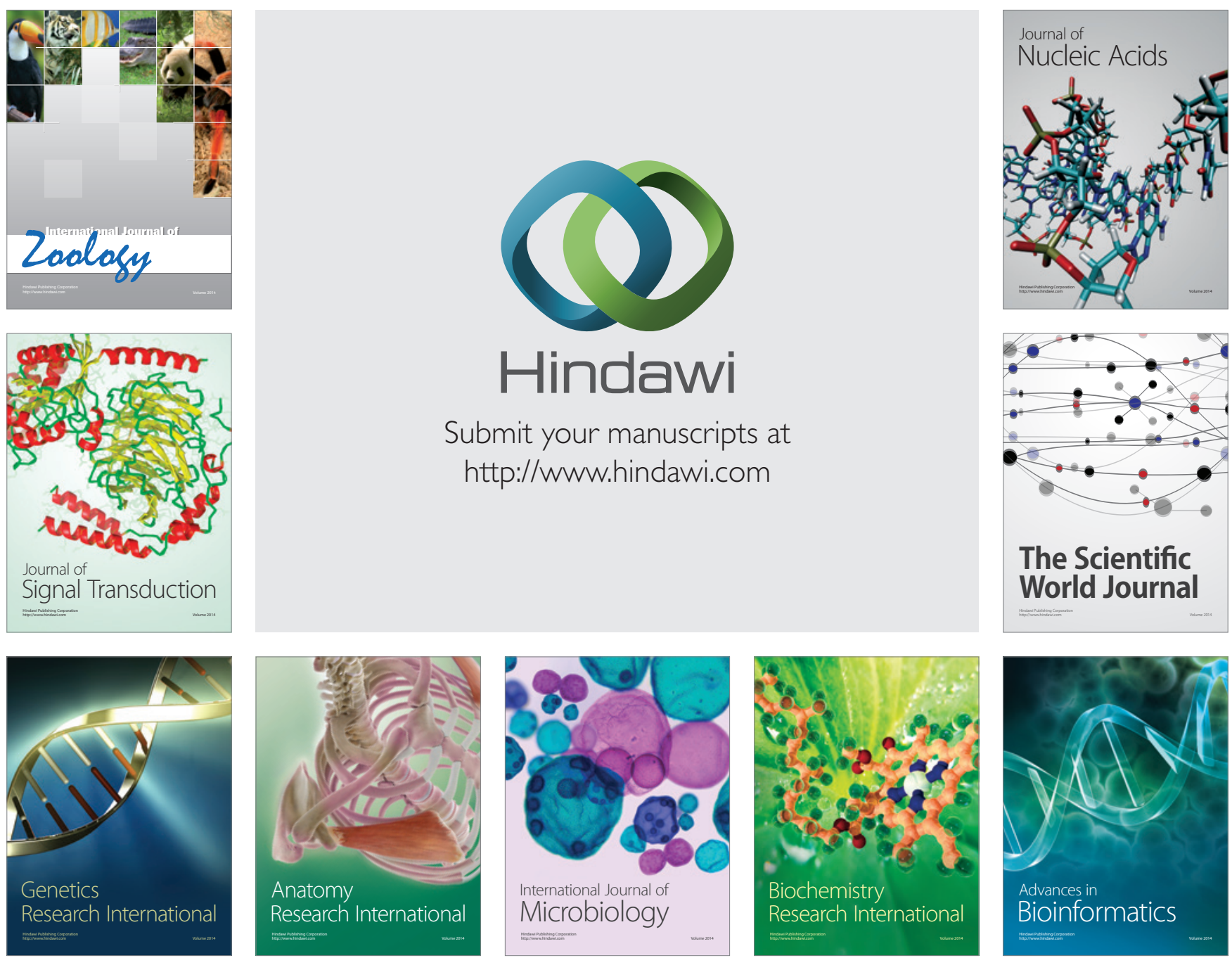

The Scientific World Journal
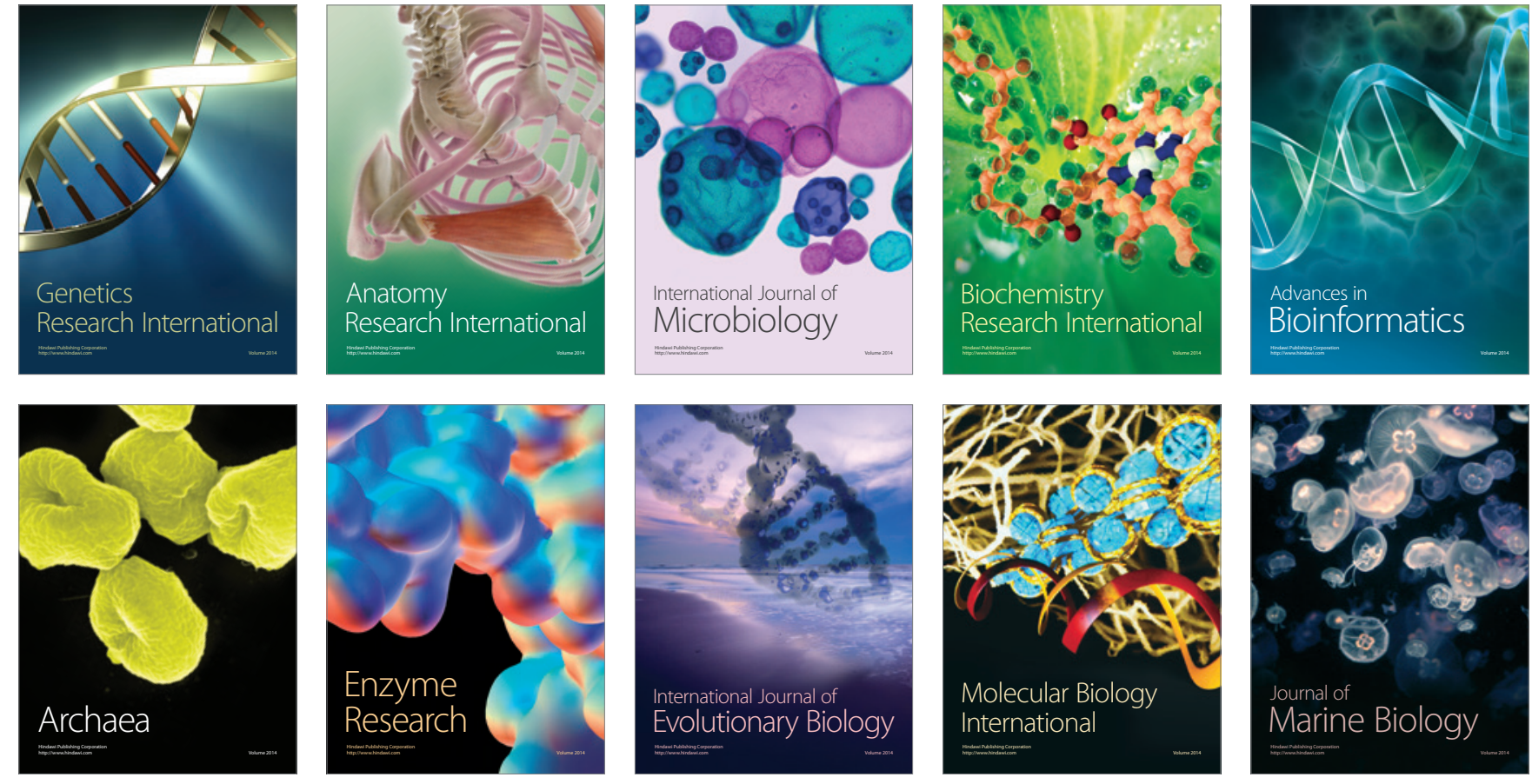